Paulina Forma

https://doi.org/10.26881/pwe.2018.43.12

ORCID: 0000-0001-5634-9250

Uniwersytet Jana Kochanowskiego w Kielcach

formapaulina.uhp@wp.pl

Dorota Beltkiewicz

Akademia Ignatianum w Krakowie

\title{
Bajka terapeutyczna jako medium edukacyjne: wzorce społeczne, kulturowe i językowe
}

\section{Summary}

Therapeutic story as an educational medium: social, cultural and language patterns

The idea of education with the use of educational media is not new, however contemporary teaching and upbringing require innovative forms in order to engage the recipients and raise the effectiveness of the process. A novel tool of influencing a child of a pre- and early school age is a therapeutic story, often being presented in a multimedia form. It is a carrier of social, cultural and language patterns. The child, through the identification with the main character, assumes the models of behaviour as well as adopts an active, creative and rational attitude towards difficult situations which may happen or happened. The mechanism of the identification of the recipient with the protagonist is stimulated by interaction, which is supported by the multimedia form. Tasks and games which are incorporated in the plot give the child the feeling of being in charge and the sense of success. Announcements made by the protagonist (inquiries, praise) strengthen the bond between the child and the fairy-tale character. Psychoeducational tales are used for prevention purposes, while psychotherapeutic and relaxation ones are implemented in therapy for the regeneration of human reserves.

Keywords: media pedagogy, media education, multimedia, preschool age, early school age, fairy-tale therapy, therapeutic story

Słowa kluczowe: pedagogika mediów, edukacja medialna, multimedia, wiek przedszkolny, wiek wczesnoszkolny, bajkoterapia, bajka terapeutyczna

\section{Wstęp}

Idea edukacji wykorzystującej media edukacyjne nie jest nową, jednak współczesne nauczanie i wychowanie wymaga nowatorskich form w celu zaangażowania odbiorców i podniesienia efektywności tego procesu. Nowatorskim narzędziem oddziaływania na dziecko w wieku przedszkolnym i wczesnoszkolnym jest bajka terapeutyczna, często prezentowana w formie multimedialnej. Celem niniejszego artykułu jest ukazanie bajki terapeutycznej jako medium edukacyjnego oraz nośnik wzorców społecznych, kulturowych i językowych. 
Pragniemy podkreślić, iż dziecko, poprzez identyfikację z głównym bohaterem bajki, przyjmuje modele zachowań, a także aktywne, twórcze i racjonalne podejście do trudnych sytuacji, które mogą się zdarzyć lub się wydarzyły. Mechanizm identyfikacji odbiorcy z protagonistą stymulowany jest interakcją, którą wspiera forma multimedialna. Zadania i gry, które są zawarte w fabule, dają dziecku poczucie sukcesu i bycia odpowiedzialnym. Pytania i pochwały formułowane przez protagonistę wzmacniają więź między dzieckiem a baśniową postacią. Ponadto wskazujemy na cele profilaktyczne bajki terapeutycznej i wykorzystywanie opowieści psychoedukacyjnych, psychoterapeutycznych i relaksacyjnych w terapii regeneracji zasobów ludzkich.

\section{Pedagogika mediów}

Rozwój techniki, nowych technologii i mediów, ściśle związany z dynamicznymi przemianami społecznymi i kulturowymi, przyczynił się do powstania pedagogiki mediów. Ma ona charakter interdyscyplinarny, korzysta z dorobku: psychologii, socjologii, antropologii kultury, filozofii czy techniki (zwłaszcza informatyki i telekomunikacji), teoretyczny fundament buduje także $\mathrm{w}$ odniesieniu do teorii komunikacji, teorii informacji, teorii oddziaływań społecznych, teorii socjalizacji, semiologii czy socjolingwistyki (Osmańska-Furmanek, Furmanek 2006: 295). Obszarem zainteresowań pedagogiki medialnej są zjawiska związane z oddziaływaniem na wszystkie sfery funkcjonowania człowieka:

- bezpośrednim - przebiegającym w kontakcie człowiek-medium (uwzględniając wszystkie formy i konfiguracje tej interakcji),

- wtórnym - wynikającym ze zmian środowiska życia zaistniałych pod wpływem mediów i rozwoju technologii informacyjno-komunikacyjnych (Osmańska-Furmanek, Furmanek 2006: 296).

Media wywierają wpływ nie tylko na skuteczność procesu kształcenia (co wydaje się być nadrzędnym przedmiotem zainteresowań pedagogiki mediów), ale przede wszystkim wpływają na kształtowanie systemu wartości, przekonań i postaw odbiorców. Potrzebne i zasadne stało się zatem rozwijanie pedagogiki medialnej jako nauki zajmującej się mediami w ich rolach dydaktycznych i wychowawczych (Strykowski 2002).

L. Bandura (1983), który jako pierwszy wprowadził na grunt polski termin ,pedagogika medialna", wymienił następujące zadania tej subdyscypliny pedagogiki:

- poszukiwanie metodycznych koncepcji stosowania mediów w procesie kształcenia (to jest w nauczaniu i uczeniu się),

- konstruowanie i wzajemnie powiązanie mediów w celu dostosowania się do poziomu osób kształcących się (celem zapewnienia im optymalnych wyników) (Osmańska-Furmanek, Furmanek 2006: 297).

Badania mediów w pedagogice dotyczyć mogą różnych obszarów; wyróżnić można kilka ich nurtów:

- media jako narzędzia/instrumentarium nauczyciela/pedagoga (obiekt badań - zastosowania edukacyjne mediów),

- zagrożenia i niebezpieczeństwa wynikające z kontaktu z mediami, 
- tworzenie i badanie instrumentarium teoretycznego i praktycznego w aspekcie celowego przygotowania człowieka do aktywnego i świadomego odbioru przekazów medialnych oraz tworzenia własnych przekazów (Osmańska-Furmanek, Furmanek 2006: 296).

\section{Edukacja medialna}

Praktyczną stroną pedagogiki medialnej jest, jak stwierdzają W. Osmańska-Furmanek i M. Furmanek (2006), edukacja medialna będąca „kluczem do rozumienia i konstruowania znaczeń rzeczywistości zdominowanej przez kulturę medialną”.

Wedle J. Gajdy (2002) edukacja medialna „sprowadza się do uczenia się najnowszej technologii kształcenia, do selektywnego i aktywnego odbioru treści przekazywanych przez media oraz współtworzenia i tworzenia programów edukacyjnych. Edukacja ta musi w głównej mierze koncentrować się na kulturze ogólnej”.

Według B. Siemienieckiego (2002) ,edukacja medialna obejmuje takie obszary, jak: kognitywistyczną teorię komunikacji medialnej, teorię i praktykę kultury mass mediów, technologię informacyjną, metodykę kształcenia medialnego". Teoria kognitywistyczna komunikacji medialnej obejmuje całokształt problemów związanych z odbiorem komunikatów medialnych przez mózg człowieka. W rozumieniu autora kognitywistyczna teoria komunikacji medialnej obejmuje „,całokształt problemów związanych z odbiorem komunikatów, zaś teoria i praktyka massmediów poświęcona jest problemom tworzenia" (Siemieniecki 2002).

W. Osmańska-Furmanek i M. Furmanek stwierdzają, że wiodącym zadaniem edukacji medialnej jest „wskazanie miejsca mediów w kulturze, zapoznanie z możliwościami mediów i sposobem ich wykorzystania w procesie kształcenia i samokształcenia, wykształcenie umiejętności porozumiewania się człowieka z komputerem i drugim człowiekiem przez sieć komputerową, interpretacji komunikatów medialnych, a wypadku multimediów - umiejętności posłużenia technologią informacyjną jako narzędziem rozwoju intelektualnego" (Osmańska-Furmanek, Furmanek 2006: 296).

\section{Media edukacyjne}

Idea kształcenia dzięki zastosowaniu mediów edukacyjnych nie jest nowa, niemniej współczesne nauczanie i wychowanie wymaga innowacyjnych form w celu zwiększenia zaangażowania odbiorców, a tym samym podniesienia efektywności procesu nauczania i wychowania. W. Osmańska-Furmanek zwraca uwagę, na „kompleksowość zastosowań mediów edukacyjnych zdeterminowaną interakcją czterech istotnych czynników:

- systemu ikoniczno-symbolicznego danego medium (jego cechy),

- treści przekazywanego komunikatu (cechy nabyte medium),

- realizowanego zadania dydaktycznego.

- osobowości uczącego się (Osmańska-Furmanek 1999).

Nowatorskim narzędziem oddziaływania na dziecko w wieku przedszkolnym i wczesnoszkolnym jest bajka terapeutyczna (często prezentowana w formie multimedialnej). 


\section{Bajka terapeutyczna}

Zastosowanie biblioterapii jako formy oddziaływania na odbiorcę poprzez wybrany tekst jest coraz powszechniejsze. Według A. Bautsz-Sontag (2013) działania biblioterapeutyczne „zaznaczają się jako bezpieczne, niezagrażające i nieinwazyjne doświadczenia”. Dla dzieci w wieku przedszkolnym i wczesnoszkolnym najbardziej odpowiednią formą jest bajkoterapia, użycie bajek terapeutycznych (utworów właściwie skomponowanych i dobranych do predyspozycji i potrzeb małego odbiorcy). Utwory te mogą pełnić różne funkcje. M. Molicka wyróżniła następujące ich funkcje (2011):

- funkcję psychoedukacyjną,

- funkcję psychoterapeutyczną,

- funkcję relaksacyjną.

W celach profilaktycznych najczęściej stosowane są bajki psychoedukacyjne (prezentacja postaw i zachowań wobec sytuacji trudnej mogącej się wydarzyć), zaś w terapii bajki psychoterapeutyczne (ukazanie możliwych form radzenia sobie z trudnymi okolicznościami, które już nastąpiły). Bajki relaksacyjne wykorzystuje się w celu regeneracji zasobów (rozluźnienie, uspokojenie, odprężenie). Mogą być one stosowane zarówno podczas zajęć indywidualnych, jak i grupowych.

Podstawowym mechanizmem warunkującym skuteczność bajkoterapii jest identyfikacja dziecka z glównym bohaterem utworu, który znajduje się w podobnej (potencjalnej dla zaistniałej) sytuacji.

D. Bełtkiewicz (2017) stwierdza: „Wzorce zawarte w bajkach terapeutycznych dotyczyć mogą kultury, relacji społecznych, języka. Owszem, płaszczyzny te tworzą nierozerwalną triadę, niemniej w zależności od indywidualnej sytuacji odbiorcy, dobrane powinny zostać bajki terapeutyczne eksponujące konkretny rodzaj wzorca".

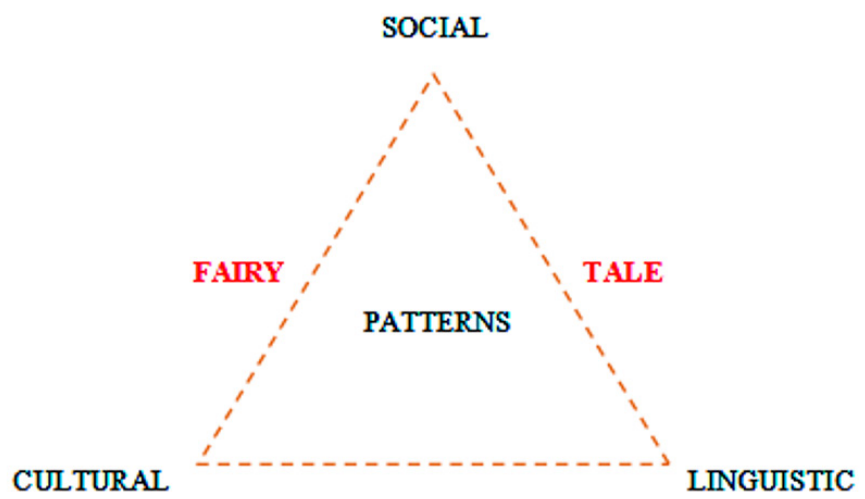

THERAPY

Rys. 1. Triada wzorców prezentowanych w bajkach terapeutycznych

Źródło: (Bełtkiewicz 2017). 


\section{Wzorce spoleczne}

Wzorce społeczne, pierwotnie w sposób naturalny kształtowane są w pierwszej i najmniejszej grupie społecznej, jaką jest rodzina. P. Forma stwierdza: „Rodzina stanowi najbardziej znaczące środowisko wychowawcze dla młodego człowieka, ponieważ jest ona przestrzenią bezpośrednio zinternalizowaną we wczesnym dzieciństwie" (Forma 2014a).

Włączenie bajek terapeutycznych jako dodatkowej stymulacji rozwoju społecznego dziecka wzmaga proces socjalizacji. Wedle S. Górskiego: „Potrzeby dziecka, zwłaszcza psychospołeczne, są wyjątkowo silne i, w porównaniu z potrzebami biologicznymi, znacznie rzadziej bywają zaspokajane w rodzinie, choć kojarzy się nam ona ze wszystkim, co najlepsze i najważniejsze. Tymczasem rodzina, podobnie jak każda grupa społeczna, też jest terenem walki jej członków o zaspokojenie swoich potrzeb." W takim przypadku (gdy środowisko rodzinne swoją rolę spełnia nieprawidłowo albo niewystarczająco) bajki terapeutyczne mogą być stosowane przez psychologów, psychoterapeutów.

Jako drugą grupę mającą istotny wpływ na socjalizację jednostki P. Forma (2015) wskazuje społeczność szkolną (klasa, grupa rówieśnicza). D. Bełtkiewicz (2017) podkreśla, że: „Bajki terapeutyczne stymulują empatię, ukazują szerszy wymiar funkcjonowania społecznego (nie jedynie koegzystencję, ale kooperację), ukazują nie tylko neutralne, bezkonfliktowe działanie, ale zalety płynące z integracji, współpracy, pomocy. Celem bajkoterapii jest stymulacja samodzielności, aktywności, kreatywności, lecz bardzo często w fabule inne postaci bajkowe inspirują, wspierają (nie wyręczając) głównego bohatera w pokonywaniu trudności”.

\section{Wzorce kulturowe}

W dobie globalizacji, łączenia i przenikania się kultur, lecz także powszechnego relatywizmu, wyzwolenia z norm, istotne jest ukazanie i utrwalenie młodym pokoleniom wypracowanych przez wieki wzorców wyrastających z kultury, w której żyją. W bajkoterapii wzorce te mogą dotyczyć:

- kultury osobistej (właściwe wysławianie się i zachowanie, odpowiedni ubiór, szacunek do starszych),

- kultury społecznej (poszanowanie tradycji, obrzędów, zwyczajów) (Bełtkiewicz 2017).

Utrwalanie rodzimych wzorców kulturowych nie może jednak wiązać się z wypieraniem, odrzucaniem oraz wrogim nastawieniem do modeli typowych dla innych kultur. Bajki terapeutyczne służyć mają także obalaniu mitów i stereotypów. J.F. Nosowicz zwraca uwagę, że „Samo zjawisko »stereotypu« jest obiektem badań nie tylko w pracach lingwistów, lecz również socjologów, etnografów, kognitologów, psychologów, etnopsycholingwistów. (...) Najczęściej mówi się o stereotypach narodowych, czyli naszych wyobrażeniach dotyczących innych narodów. Tworzenie stereotypów jest naturalną ludzką skłonnością i takiemu upraszczaniu przekazu podlegają wszelkie ludzkie wyobrażenia 
o otaczającym świecie, zarówno przyrody jak i społeczeństwa. Zazwyczaj oparte są na niepełnej lub fałszywej wiedzy o świecie, utrwalonej przez tradycję i, niestety, ciężko podlegającej zmianom" (Nosowicz 2013). W środowiskach multikulturowych konieczny jest szacunek, który „niesie przesłane symetrii i wzajemności” (Koźmińska, Olszewska 2007). J.F. Nosowicz (2013) podkreśla: „W europejskiej szkole badaczy przedmiotu przyjęło się jednak traktować uprzedzenia jako zjawisko negatywne. Mamy tu bowiem do czynienia z negatywną postawą, niechęcią lub dyskryminowaniem". Uprzedzenia mogą okazać się niebezpieczne, powinny być niwelowane u młodych pokoleń jak najwcześniej, również za pomocą bajkoterapii (Bełtkiewicz 2013b).

\section{Wzorce jezykowe}

Bajki terapeutyczne mogą także koncentrować się na zagadnieniach językowych. Od sposobu komunikacji werbalnej zależy między innymi:

- integracja z otoczeniem (nawiązywanie i podtrzymywanie relacji),

- jakość kontaktów międzyludzkich (zrozumienie),

- ocena i samoocena jednostki (sposób wypowiadania się jako element charakterystyki osoby) (Bełtkiewicz 2017).

Język wiąże się z emocjami, zaburzona mowa często sprzężona jest z lękiem. Dzieci z wadami wymowy, zaburzeniami komunikacji językowej bywają stygmatyzowane w grupie rówieśniczej, co wpływa ujemnie na ich samoocenę i samopoczucie. Logopedyczne bajki terapeutyczne przedstawiają przygody bohatera, który musi poradzić sobie z problemem językowym (i równocześnie emocjonalnym) (Bełtkiewicz 2013a). Utwory te wskazują na wzorzec językowy (cel działań), prezentując przy tym w formie atrakcyjnych ćwiczeń, gier, animacji środki do jego osiągnięcia. Ten rodzaj bajek terapeutycznych dedykowany jest głównie dzieciom z wadami wymowy, zaburzeniem płynności mowy, jak i dzieciom dwujęzycznym, które często mają problem z różnicowaniem niuansów fonetycznych we wspótistniejących w ich otoczeniu językach (Bełtkiewicz 2015).

\section{Sila przekazu multimedialnego}

Prowadzone badania wykazały większą skuteczność bajek terapeutycznych multimedialnych (wizualizacja bohatera, zadania i ćwiczenia przedstawione w formie angażujących gier, pełna interakcja, komunikacja z postacią - pytania o samopoczucie, pochwały, komunikaty motywacyjne) niż tradycyjnych (odczytanie, ewentualne ilustracje do tekstu). Wersja nowoczesna umożliwia poznawanie przygód bohatera wielozmysłowo, przez co identyfikacja z postacią bajkową jest szybsza i silniejsza. Owszem, przestymulowanie dziecka nowymi technologiami prowadzi do niekorzystnych, często nieodwracalnych zmian. Wersja ta jest dozwolona dla dzieci począwszy od wieku przedszkolnego, w rozsądnej częstotliwości stosowania. Multimedia stały się integralną częścią procesu edukacji, wychowania, terapii. Już na początku XXI wieku J. Surowaniec pisał o nowych technologiach: „W minionym 
dziesięcioleciu rozwój technologii informatycznych przebiegał wręcz lawinowo. Mówi się nawet o galopadzie technologicznej" (Surowaniec 2001). Nie znaczy to jednak, że multibooki powinny całkowicie zastąpić tradycyjną lekturę. Niewątpliwie tradycyjna wersja książki posiada liczne zalety:

- rozwojowe: pobudza wyobraźnię, pozwala skupić się na sferze językowej,

- organizacyjne: nie wymaga organizacji warunków i sprzętu do prezentacji dziecku.

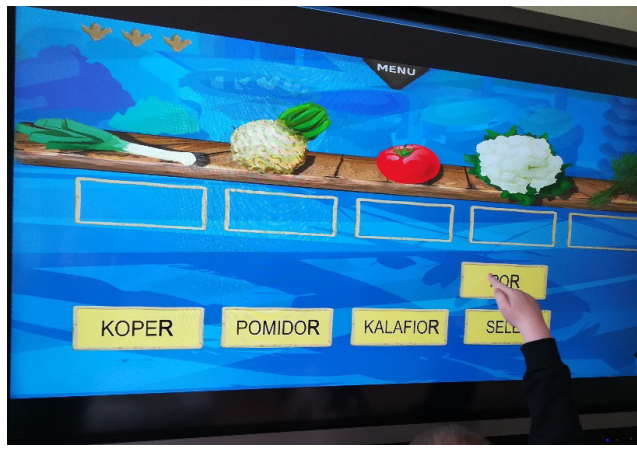

Fot. 1. Wykorzystanie tablicy interaktywnej, materiały własne (Logopedyczna bajka terapeutyczna „Rrromek i Rrradek - głoska r" - Wydawnictwo DoDo4Story)

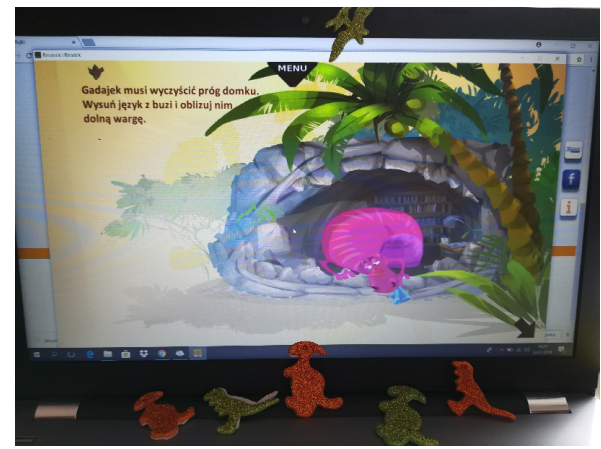

Fot. 2. Wykorzystanie komputera, materiały własne (Logopedyczna bajka terapeutyczna „Rrromek i Rrradek - głoska r" - Wydawnictwo DoDo4Story)

\section{Sila międzyludzkich relacji}

Prowadzone i rekomendowane przez autorki działania z wykorzystaniem bajek terapeutycznych stanowią, co warto podkreślić, wsparcie dla tradycyjnych działań edukacyjnych i wychowawczych. Multimedialna forma nośnika treści nie może zastąpić naturalnej relacji, jaka tworzy się między dzieckiem a rodzicem, nauczycielem, pedagogiem, terapeutą.

P. Forma i B. Matyjas stwierdzają: „Cyfryzacja życia występuje we wszystkich jego aspektach, w tym edukacji i wychowaniu, a także sprawia, że środki masowego przekazu i multimedia mają większy wpływ niż rodzina. Wpływ mediów na młodych ludzi, ich osobowości, postawy, zachowania i opinie mogą być pozytywne (wraz z wszelkimi możliwościami edukacyjnymi, terapeutycznymi lub kompensacyjnymi zapewnianymi przez media). Z drugiej strony media stanowią zagrożenie dla intelektualnej, moralnej, emocjonalnej, fizycznej i praktycznej sfery życia (Forma, Matyjas 2014: 985).

Dziecko nie może być pozostawione bez opieki w trakcie korzystania z bajki terapeutycznej. Bohater bajkowy inspiruje, przekazuje wzorce i modele, ale konieczna jest po emisji utworu, a nawet w jej trakcie, rozmowa dziecka z dorosłym (realnym autorytetem), wyjaśniająca i podsumowująca. Zasadniczym celem bajkoterapii nie jest bowiem automatycznie przekazywanie gotowych schematów, lecz zachęta do dobrowolnego podejmowania prób dążenia do wzorca. 


\section{Podsumowanie}

Najpopularniejsza forma biblioterapii w XXI wieku w Polsce (Szulc 2011) - bajkoterapia polegająca na zastosowaniu bajek terapeutycznych (coraz częściej prezentowanych w formie interaktywnej, multimedialnej) stanowi kompletne, kompleksowe wsparcie dla nauczycieli, pedagogów, rodziców, terapeutów. Nowoczesna bajka terapeutyczna spełnia wszystkie kryteria skutecznego medium edukacyjnego, jest nośnikiem wzorców społecznych, kulturowych i językowych. Mały odbiorca, poprzez identyfikację z głównym bohaterem utworu, samodzielnie i dobrowolnie przejmuje modele zachowania, postawę aktywną, kreatywną i racjonalną wobec sytuacji trudnych mogących się wydarzyć lub zaistniałych. Mechanizm utożsamiania się odbiorcy z postacią powoduje interakcja, którą wzmacnia forma multimedialna. Włączone w fabułę zadania i gry dają dziecku poczucie sprawstwa i sukcesu. Kierowane przez postać komunikaty (zapytania, pochwały) wzmacniają więź między dzieckiem a bohaterem bajkowym. Forma multimedialna podnosi efektywność oddziaływania bajkoterapeutycznego, nie może zastępować relacji dziecko-dorosły oraz tradycyjnej lektury.

\section{Literatura}

Bautsz-Sontag A. (2013), Literatura $w$ terapii dzieci. Katowice, Uniwersytet Śląski, Oficyna Wydawnicza Wacław Walasek.

Bandura L. (1983), Pedagogika medialna. „Ruch Pedagogiczny”, nr 3-4.

Bełtkiewicz D. (2013a), A New Horizon in Logopaedics: Speech Therapeutic Story - Innovative Use of a Story in the Therapy of Children Speech Impediments, 'Procedia - Social and Behavioral Sciences', Vol. 106.

Bełtkiewicz D. (2013b), Potrzeba tolerancji w środowiskach multikulturowych-bajkoterapia jako metoda wspierająca. W: N. Majchrzak, A. Zduniak (red.), Edukacja międzykulturowa w warunkach kultury globalnej. Od rozważań definicyjnych do praktycznych zastosowań. Poznań, Wydawnictwo Wyższej Szkoły Bezpieczeństwa.

Bełtkiewicz D. (2017), Empowerment through fairy-tale therapy. Cultural, social and linguistic pattern. W: Z. Mlčák (red.), Psychologické aspekty pomáhání. Ostrava, Ostravská univerzita.

Forma P. (2014), Przesunięcie socjalizacyjne dzieci i młodzieży we wspótczesnej rodzinie polskiej. „Wychowanie w Rodzinie”, 2/2014.

Forma P. (2015), Social Roles of the Child Brought Up in Multi-Child Family: The Role of Student, the Role of Friend, the Role of School Community Member. "Journal of Modern Education Review", Vol. 5, No. 5.

Forma P., Matyjas B. (2014), Digitalization of upbringing and education in relation to shifted socialisation of Polish students. "Procedia - Social and Behavioral Sciences", vol. 176.

Gajda J. (2000), Kulturotwórcze i edukacyjne funkcje mass mediów. W: W. Strykowski (red.), Media a edukacja. Poznań, Wydawnictwo eMPi2.

Gajda J., Juszczyk S., Siemieniecki B., Wenta K. (red.) (2002), Edukacja medialna. Toruń, Wydawnictwo Adam Marszałek. 
Górski, S. (1986), Psychoterapia w wychowaniu. Warszawa, Instytut Wydawniczy Związków Zawodowych.

Koźmińska I., Olszewska E. (2007), Z dzieckiem w świat wartości. Warszawa. Świat Książki.

Molicka M. (2002), Bajkoterapia. O lękach dzieci i nowej metodzie terapii. Poznań, Media Rodzina.

Molicka M. (2011), Biblioterapia i bajkoterapia. Rola literatury w procesie zmiany rozumienia świata społecznego i siebie. Poznań, Wydawnictwo Media Rodzina.

Nosowicz J.F. (2013), Edukacja regionalna w zmieniajacej się (inter)kulturze. W: I.H. Pugacewicz, E.B. Zybert (prac. zbior.), Biblioteki, tożsamość, kultura. Warszawa, Wydawnictwo Stowarzyszenia Bibliotekarzy Polskich

Osmańska-Furmanek W., Furmanek M. (2006), Pedagogika mediów. W: B. Śliwerski (red. nauk.), Pedagogika. Subdyscypliny wiedzy pedagogicznej. Gdańsk, Gdańskie Wydawnictwo Pedagogiczne.

Osmańska-Furmanek W. (1999), Nowe technologie informacyjne w edukacji. Zielona Góra, wydawnictwo LTN.

Strykowski W. (2002), Pedagogika i edukacja medialna $w$ społeczeństwie informacyjnym. W: S. Juszczyk (red.), Edukacja medialna w społeczeństwie informacyjnym. Toruń, Wydawnictwo Adam Marszałek.

Surowaniec J. (2001), Informacja internetowa w edukacji logopedycznej. W: J. Kida (red.) Literatura i sztuka a wychowanie. Rzeszów, Wydawnictwo Wyższej Szkoły Pedagogicznej.

Szulc W. (2011), Arteterapia. Narodziny idei, ewolucja teorii, rozwój praktyki. Warszawa, Wydawnictwo Difin. 